\title{
Modified high-strength concrete with the addition of CONPLAST SP430
}

\author{
Baxauatdin Kalbaev $^{1 \mathrm{a}}$, Gulzar Utegenova ${ }^{1 \mathrm{~b}}$, A. Ilyasov $^{1 \mathrm{c}}$, Mikhail Gandjuntsev ${ }^{2 \mathrm{~d}}$ \\ ${ }^{1}$ Karakalpak state university named after Berdakh, 230100 Academician Ch. Abdirov 1, Nukus, \\ Karakalpakstan, Uzbekistan \\ ${ }^{2}$ Moscow State University of Civil Engineering, Yaroslavskoe shosse, 26, Moscow, 129337, Russia
}

\begin{abstract}
In most high-strength concrete technologies, high-quality Portland cements are used, which is not always achievable in conditions of a shortage of such binders.

The research's purpose is to obtain high-strength concrete based on ordinary Portland cement of the M400 brand. To achieve this goal, the possibility of using the superplasticizer Conplast SP430 was studied.

The research was carried out using standard methods, like using mathematical planning and result's analytical processing.

The implementation of the experiment allowed us to determine the optimal values of the basic composition of concrete: the consumption of superplasticizer- $1.0 \%$ of the mass of cement; the consumption of cement$485 \mathrm{~kg} / \mathrm{m} 3$, the ratio of sand/crushed stone-0.36. At the optimal value of the parameters, the achieved maximum compressive strength was 58.8 $\mathrm{MPa}$.

The novelty is the justification of the possibility of obtaining high-strength concretes using Portland cement with an activity not exceeding $40 \mathrm{MPa}$ based on the use of a new generation superplasticizer and the development of the basics of the method for selecting the composition of concrete.

The significance of the result is due to the expansion of the possibility of using ordinary Portland cement for the production of products and structures with the use of high-strength concrete.
\end{abstract}

\section{Introduction}

In the technologies of modern concrete and reinforced concrete, three priority areas can be identified: the development of textile-concrete technologies, the development of technologies and formulations for 3D printing, and the improvement of modern high-strength concrete technologies. The main directions in the development of high-strength concrete technology are the development of modified cement systems to improve the efficiency of build-

\footnotetext{
${ }^{\text {a }}$ Corresponding author: kalbaevbaxauatdin@gmail.com

${ }^{\mathrm{b}}$ Corresponding author: u.gulzar@yandex.ru

${ }^{\mathrm{c}}$ Corresponding author: allanazar86@mail.ru

${ }^{\mathrm{d}}$ Corresponding author: oppmgsu2014@yandex.ru
} 
ing composites; shortening the service life of reinforced concrete and concrete structures. Concrete quality improvement methods consist in the use of high-tech equipment, modern production technologies, and the use of high-quality materials and additives of individual and multifunctional action. The trend of modern development of concrete technology is focused on the gradual replacement of traditional concrete with multicomponent ones. First of all, concrete modification will be carried out by introducing multicomponent complex additives of poly functional action [1,2].

Obtaining high-strength and high-quality cement concretes is possible with the purposeful formation of the cement stone structure, characterized by a low proportion of capillary pores, an increased content of hydrate neoplasms, especially a reduced basicity. Modification of cement concretes with complex additives is the most affordable and simple way to significantly increase the efficiency of cement concretes and can be successfully used for these purposes [3, 4]. From the point of view of saving resources, improving technological processes and solving problems related to environmental protection, it is advisable to study the use of secondary products and concrete scrap in the composition of concrete modified mixtures $[5,6]$.

The use of superplasticizers in the production of precast concrete is carried out in the following main directions: to reduce the consumption of cement; to increase the mobility of the concrete mixture while maintaining the physical and mechanical properties of concrete and dramatically reducing the complexity of forming structures; to obtain high-strength concretes; and, finally, to obtain concretes with improved physical and mechanical properties and durability $[7,8]$.

Conplast SP430 is a highly effective complex chemical modifier of hyper plasticizing action, the area of rational use of which is self-compacting concrete mixes and highstrength concretes based on them. To obtain self-compacting high-strength concrete with Conplast SP430, it is recommended to use cements not lower than M 500, Added Mixture is 0 . Such cements are not produced everywhere and not in the required volumes, in addition, as a result of logistics operations (transportation and storage), the properties of cement may degrade and its grade may decrease $[9,10]$.

The purpose of the research presented in the article was to obtain a self-compaction layer. Concrete mix, high-strength concrete or modified concrete of increased strength based on ordinary Portland cement of the M 400 brand with the use of a new generation chemical additive with a super plasticizing effect Conplast SP430.

The scientific novelty of the research consisted in forming mathematical models of strength and waterproofness of modified concrete depending on structure-forming factors and optimizing the composition of concrete B30 on ordinary Portland cement of the M400 brand.

\section{Materials and Methods}

Experimental studies were conducted to determine the effect of the new generation Conplast SP430 super plasticizing additive. On the technological properties of the concrete mix, physical and mechanical properties and durability of modified concretes, as well as on the structure and properties of cement binders of ordinary brands of domestic production.

When performing experimental studies, M400 grade Portland cement of the following mineralogical composition was used as a binder: $\mathrm{C}_{3} \mathrm{~S}-57.57 .5 \%, \mathrm{C}_{2} \mathrm{~S}-1717.8 \%, \mathrm{C}_{3} \mathrm{~A}-$ 4.4.7\%, and $\mathrm{C}_{4} \mathrm{AF}-12.5 \%$. Sand and crushed stone were used as inert materials. The super plasticizer Conplast SP430 (Great Britain) was used as a modifying additive for concrete Conplast.

Preparation of concrete mixes, and studies of the properties of the material were carried out according to the methods recommended by the standards. The core of the research was 
the use of methods of mathematical planning of the experiment and processing of its results. Mathematical planning methods are widely used in solving statistical problems in all fields of knowledge, science and technology. These methods are based on the representation of the process (model, phenomenon) as a "black box". A "black box" is a cybernetic model of a process that has "inputs" (factors that vary during the experiment) and "outputs" (response functions). At the same time, all processes inside the "black box" are not considered. This method is widely used in engineering, including construction materials science $[11,12]$.

Mathematical modeling of the strength of filled concrete was performed in order to optimize its composition. To describe the strength of concrete at any point in the experimental area, we used second-order polynomial models with three alternating factors. Factors such as the content of: super plasticizer were selected as independent variables $(0.8-1.2 \%)$; cement consumption $\left(400-500 \mathrm{~kg} / \mathrm{m}^{3}\right)$; sand-to-gravel ratio $(0.30-0.40)$. The output parameters of the response functions were chosen: concrete compressive strength at 7 and 28 days of age $\left(\mathrm{R}_{7}, \mathrm{R}_{28}\right)$. The levels of variations and other independent variables are shown in table. 1 . The adequacy of the obtained models was evaluated by the Fisher criterion.

Table 1. Levels of variation of independent variables

\begin{tabular}{|l|l|l|l|l|}
\hline Factors & Naming of factors & \multicolumn{3}{|l|}{ Variation levels } \\
\cline { 3 - 5 } & & -1 & 0 & +1 \\
\hline $\mathrm{X}_{1}$ & $\begin{array}{l}\text { Consumption of super plasticizer, \% by weight of } \\
\text { cement }\end{array}$ & 0.8 & 1.0 & 1.2 \\
\hline $\mathrm{X}_{2}$ & Consumption of Portland cement, $\mathrm{kg} / \mathrm{m}^{3}$ & 400 & 450 & 500 \\
\hline $\mathrm{X}_{3}$ & $\begin{array}{l}\text { The ratio of the mass of sand to the mass of } \\
\text { crushed stone S/Cs }\end{array}$ & 0.30 & 0.35 & 0.40 \\
\hline
\end{tabular}

\section{Experiments and Results}

The effect of Conplast SP430 super plasticizer Conplast on changes in the normal density and setting time of cement dough was previously studied. It was found that the introduction of SP430 super plasticizer into the cement dough reduces the water demand of the cement dough by 30.4-33.0\%, depending on the type of cement used. The setting time of cement dough with a super plasticizer is somewhat different from the control stage. So, the beginning of setting of cement dough occurs 38-53 min. later than the composition without additives, and the end of setting - later for 50-66 min. Conplast SP430 most effectively reduces the water demand of cement dough in the amount of $1.0-1.2 \%$ of the cement mass. The results of tests of cement stone for compression showed that the optimal content of the additive Conplast SP430 is the content of $1 \%$ by weight of cement

The results of mathematical planning of experiments were processed, which made it possible to obtain mathematical dependencies, which, after checking the significance of the coefficients, took the following form:

$$
\begin{aligned}
& \mathrm{R}_{7}=25.8+9.5 \mathrm{X}_{1}+8.1 \mathrm{X}_{2}+6.3 \mathrm{X}_{3}+3.8 \mathrm{X}_{2} \mathrm{X}_{3}-8.2 \mathrm{X}_{1}^{2} \\
& \mathrm{R}_{28}=42+10.7 \mathrm{X}_{1}+8.2 \mathrm{X}_{2}+7.3 \mathrm{X}_{3}+5.5 \mathrm{X}_{2} \mathrm{X}_{3}-4.7 \mathrm{X}_{1} \mathrm{X}_{3}
\end{aligned}
$$

\section{Discussion}


As follows from the obtained regression equations, with an increase in the consumption of super plasticizer and cement consumption, the concrete strength increases at all times of hardening (coefficients at $\mathrm{X}_{1}$ and $\mathrm{X}_{2}$ with a positive sign). At the same time, when the super plasticizer runs high, the strength may decrease (the coefficient at with a negative sign). The decrease in the strength of concrete at increased dosages of super plasticizer can be explained by the blocking effect of the molecules of this chemical additive on the Portland cement particles, which is especially evident with increased consumption of Portland cement in the concrete composition.

When analyzing the regression equations (1) and (2), positive effects of the combined influence of factors are established. For strength at the early stages of hardening, this effect is established for the combined effect of the Portland cement consumption and sand-to-sand ratio (coefficient at $\mathrm{X}_{2} \mathrm{X}_{3}$ ), which is explained by a more isotropic distribution of fine aggregate between large ones under the plasticizing effect on the cement dough. For the strength of concrete at the age of 28 days, the co-effect of the local influence of Portland cement consumption and the ratio of sand to crushed stone is also positive. The negative effect of the combined effect of increasing the consumption of super plasticizer on the ratio of sand to crushed stone (coefficient at $\mathrm{X}_{2} \mathrm{X}_{3}$ with a minus sign) is also established, which is explained by the possible deterioration of the contact between the binder and aggregate particles. The presence of positive effects of joint influence allows us to assume the possibility of synergistic effects, and the presence of negative influence - the possibility of antagonistic effects, which may be the goal of further scientific research aimed at studying the regularities of the formation of the concrete structure.

The mathematical polynomial (1) contains the coefficient at in the first and second powers, which makes it possible to apply methods of analytical optimization $\mathrm{X}_{1}$ of the obtained dependences, when considering them as mathematical functions of several (in this case, three variables).

To determine the optimal value of the factor $\mathrm{X}_{1}$, using algebraic methods, we need to differentiate function (1) with respect to $\mathrm{X}_{1}$ and equate the result to 0 :

$$
\partial R_{7} / \partial X_{1}=9.5-16.4 X_{1}=0 \rightarrow X_{1}=\frac{9.5}{16.4}=0.6
$$

To get the optimized functions (1) and (2), you need to put the calculated optimal value $\mathrm{X}_{1}$ in their mathematical polynomials1:

$$
\begin{gathered}
\mathrm{R}_{7}=25.8+9.5 \times 0.6+8.1 \mathrm{X}_{2}+6.3 \mathrm{X}_{3}+3.8 \mathrm{X}_{2} \mathrm{X}_{3}-8.2 \times(0.6)^{2} \\
\mathrm{R}_{28}=42+10.7 \times 0.6+8.2 \mathrm{X}_{2}+7.3 \mathrm{X}_{3}+5.5 \mathrm{X}_{2} \mathrm{X}_{3}-4.7 \times 0.6
\end{gathered}
$$

As a result, we obtain $\mathrm{X}_{1}$ optimized regression equations for the strength of concrete at the age of 7 and 28 days:

$$
\begin{aligned}
& \mathrm{R}_{7}=26.8+8.1 \mathrm{X}_{2}+6.3 \mathrm{X}_{3}+3.8 \mathrm{X}_{2} \mathrm{X}_{3} \\
& \mathrm{R}_{28}=45.7+8.2 \mathrm{X}_{2}+7.3 \mathrm{X}_{3}+5.5 \mathrm{X}_{2} \mathrm{X}_{3}
\end{aligned}
$$

The natural value of the plasticizer consumption is determined based on the data in table.1: the optimal consumption of Conplast SP430 super plasticizer is $1.0-1.06 \%$ by weight of cement, which corresponds to the results of other preliminary experiments. 


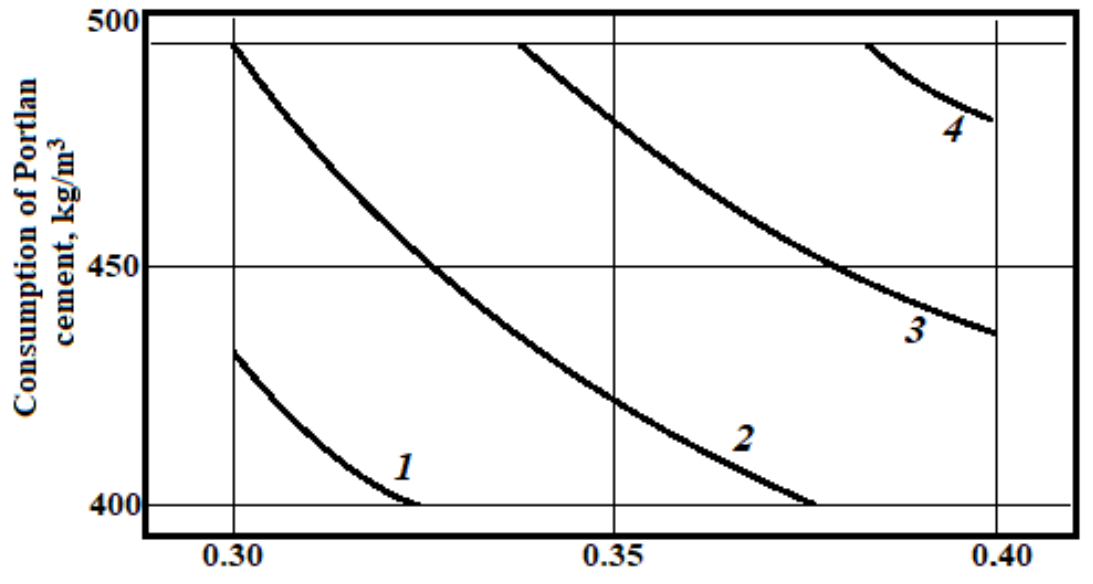

The ratio of the mass of sand to the mass of cruched stone

Fig. 1. The dependence of the compressive strength of concrete at the age of 7 days $\left(R_{7}\right)$ on the consumption of Portland cement and the ratio of sand to cement in the molding mixture. Strength values, MPa: $1-20 ; 2-24: 3-28 ; 4-32$

Graphical interpretation of the optimized polynomials (3) and (4) made it possible to construct nomograms for determining the strength of concrete at the age of 7 and 28 days (figs.1 and 2). Attention is drawn to the similar nature of the dependence of strength on the pore flow rate of talc cement and the ratio of sand to crushed stone. The figures can be used as nomograms to determine the optimal consumption of Portland cement and the ratio of sand to crushed stone for a given concrete strength.

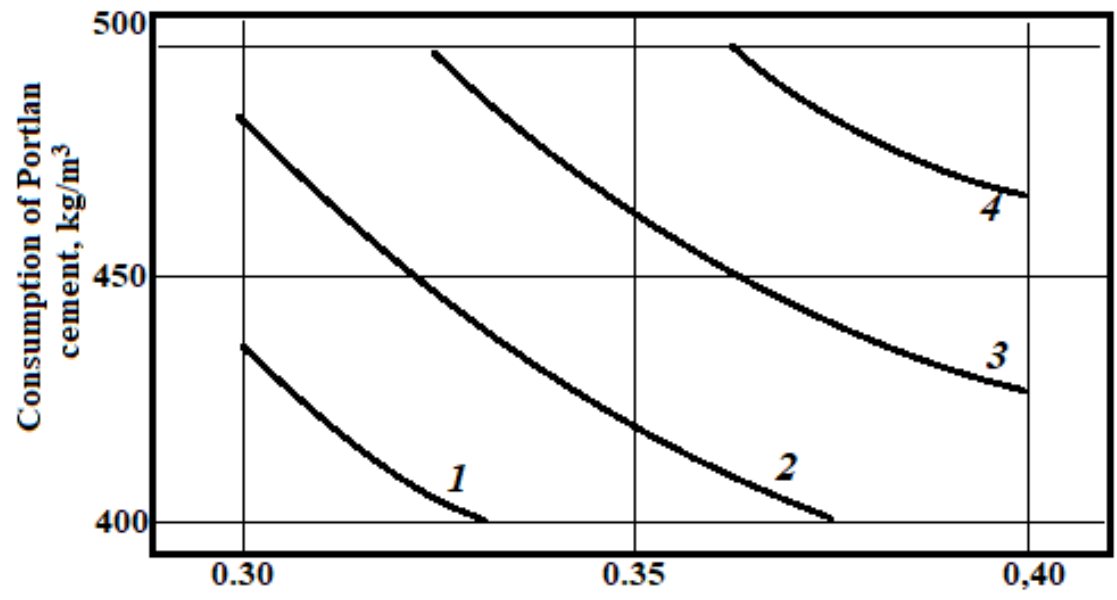

The ratio of the mass of sand to the mass of cruched stone

Fig. 2. Dependence of the compressive strength of concrete at the age of 28 days $\left(\mathrm{R}_{28}\right)$ on the consumption of Portland cement and the ratio of sand to cement in the molding mixture: Strength values, MPa: $1-34 ; 2-42: 3-54 ; 4-58$

Applying the obtained mathematical models using analytical and graph analytical methods, the optimal values of the composition of modified high-strength concrete were determined: the dosage of Conplast SP430 super plasticizer is $1.0 \%$ by weight of cement; cement consumption is $485 \mathrm{~kg} / \mathrm{m}^{3}$; the ratio of the parameters of the composition of modified 
concrete and compressive strength of $\mathrm{S} / \mathrm{Cs}$ is 0.36 . With the optimal value of the abovementioned prescription parameters of the concrete mix composition, the maximum concrete strength of $58.8 \mathrm{MPa}$ was achieved.

\section{Conclusions}

Analysis of the properties of modified concrete showed that the introduction of Conplast SP430 super plasticizer in the amount of $1.0 \%$ by weight of cement increases the mobility of cement dough from $2-3 \mathrm{~cm}$ to $27 \mathrm{~cm}$, while simultaneously increasing the strength of concrete by $7-8 \%$. The results obtained made it possible to position Conplast SP430 as a super plasticizing and super-water-reducing additive. It was found that the flow rate of finegrained concrete during bending with the additive increases by $18-42 \%, \mathrm{C}$, and the flow rate during compression of fine-grained concrete with the additive increases by $46-83 \%$. It is established that the introduction of optimal amounts of additives in the composition of heavy concrete provides the greatest increase in strength in the first three days of hardening, which is $56 \%$.

Using the method of mathematical planning of experiments, mathematical models of strength, frost resistance and water resistance of modified concrete with a superplasticizer were obtained. As a result of the analysis of the obtained mathematical models using the analytical optimization methodology, the optimal values of the composition of the modified high-strength concrete were determined, which were: for the dosage of the superplasticizer Conplast SP430 - $1.0 \%$ by weight of cement; cement consumption $-485 \mathrm{~kg} / \mathrm{m}^{3}$, the ratio of S/Cs - 0.36. At the optimal value of the modified concrete composition parameters, the achieved maximum compressive strength was $58.8 \mathrm{MPa}$.

The results show that the introduction of a super plasticizer makes it possible to produce high-strength products based on Portland cement with an activity of $40 \mathrm{MPa}$, which can be used in the construction of critical objects, including reinforced concrete structures of transport and bridge structures.

\section{References}

1. Bazhenov Yu. M., Alexandrova O. V. Nguyen Dic Vinh Kuang, Bulgakov B. I., Larsen O. A., Galtseva N. A., Galatenko D. S. High-Strength concrete materials Vietnam // Building materials. 2020. № 3. C. 32-38. DOI: https://doi.org/10.31659/0585-430X2020-779-3-32-38

2. Rimshin V. I., Truntov P. S., Ketsko E. S., Nagumanova A. S. Integrated approach to quality control of high-strength concrete during operation // Constructionamaterials. 2020. No. 6. Pp. 4-7. DOI:https://doi.org/10.31659/0585-430X-2020-781-6-4-7

3. Sinitsin D. A., Babkov V. V. [In Russian]. Sahibgareev R. R., Sahibgareev ROM. R., Rezvova V. P. the Use of self-compacting concrete mixes in the construction practice of the Republic of Bashkortostan. 2019. No. 12. Pp. 45-51. DOI: https://doi.org/10.31659/0585-430X-2019-777-12-45-51

4. Troshkina E. A., Khamidulina D. D., Nekrasova S. A. Developmenteof self-compacting stress-bearing concrete for pipe-concrete columns. 2019. № 11. C. 50-54. DOI: https://doi.org/10.31659/0585-430X-2019-776-11-50-54

5. Ilyasov A. T., Kalbaev B. A. study of the influence of superplasticizer CONPLAST SP430 on the properties of concrete mixtures // methods and processes technicalenomic and technological development collection of articles on the results of the International scientific-practical conference (Chelyabinsk, June 23, 2020). - Sterlitamak: AMI, 2020. P. $18-20$ 
6. Akhverdieva T. A., Jafarov R. Influence of fine-ground mineral additives on concrete properties // Building materials. 2019. № 3. Pp. 73-76. DOI:https://doi.org/10.31659/0585-430X-2019-768-3-73-76.

7. Sidorova A. S., Antsupova S. G., Popov A. L. Physical and mechanical propertiesuof heavy concrete using local secondary raw materials // Constructionmaterials. 2020. № 9. C. 9-14. DOI: https://doi.org/10.31659/0585-430X-2020-784-9-9-14

8. Batrakov V. G. Complex modifiers of concrete properties. "Concrete and reinforcedeconcrete", 1977, No. 7, P. 4-6.

9. Nesvetaev G. V., Davidyuk A. N. Influence of some hyperplasticizers ontheporosity, humidity deformations and frost resistance of cement stone. Construction materials, 2010, no. 1, Pp. 44-46.

10. Bazhenov Yu. M. Dolgopolov N. N., Ivanov G. S. Application of superplasticizers in order to improve the technology of reinforced concrete manufacturing. "Industrial construction", 1978, No. 5, Pp. 29-32.

11. Zhukov A., Shokodko E. (2020) Mathematical Methods for Optimizing the Technologies of Building Materials in: Popovic Z., Manakov A., Breskich V. (eds) VIII International Scientific Siberian Transport Forum. TransSiberia 2019. Advances in Intelligent Systems and Computing, vol 1116. Pp. 413-421. Springer, Cham. First Online 31 January 2020. DOI: https://doi.org/10.1007/978-3-030-37919-3_40. Print ISBN978-3-030-37918-6. Online ISBN978-3-030-37919-3.

12. Zhukov A.D., Bobrova E. Yu., Bessonov I. V., Medvedev A. A. Demissi B. A., Application of statistical methods for solving problems of construction materials science / / Nanotechnologies in construction. - 2020. - Volume 12, No. 6. - Pp. 313-319. - DOI: 10.15828 / 2075-8545-2020-12-6-313-319. 